\title{
Probable imported rather than autochthonous Plasmodium vivax cases in Italy
}

E Nicastri (emanuele.nicastri@inmi.it)1

1. National Institute for Infectious Diseases (Istituto Nazionale per le Malattie Infettive, INMI) “L. Spallanzani”, Rome, Italy

Citation style for this article:

Nicastri E. Probable imported rather than autochthonous Plasmodium vivax cases in Italy. Euro Surveill. 2012;17(50):pii=20338. Available online: http://www. eurosurveillance.org/ViewArticle.aspx?Articleld=20338

To the editor: Italian colleagues describe two recent cases of probable autochthonous-introduced Plasmodium vivax malaria, suggesting that sporadic cases may be considered possible in areas with vector abundance and favourable environmental conditions [1]. Nevertheless, we have some concerns about this report: firstly, no other concurrent $P$. vivax malaria cases have been reported in the Pontine marshes or in the Calabria Region; secondly, no secondary cases have been reported to arise from the index cases; thirdly, the first patient visited Santo Domingo in the Dominican Republic in 2003, an area where malaria cases still occur; fourthly, as previously affirmed in a publication by the same group about an unusual case of late relapse of $P$. vivax four years after the acute infection [2], at least the first case could be explained as a late relapse following an asymptomatic or paucisymptomatic primary infection. In conclusion, the described cases could in our opinion be viewed as probable imported, and not autochthonous, $P$. vivax cases.
References

1. Romi R, Boccolini D, Menegon M, Rezza G. Probable autochthonous introduced malaria cases in Italy in 20092011 and the risk of local vector-borne transmission. Euro Surveill. 2012;17(48):pii=20325. Available from: http://www. eurosurveillance.org/ViewArticle.aspx?Articleld=20325

2. Durante Mangoni E, Severini C, Menegon M, Romi R, Ruggiero G, Majori G. Case report: An unusual late relapse of Plasmodium vivax malaria. Am J Trop Med Hyg. 2003;68(2):159-60. 